\title{
1 Temperature and masting control Norway spruce growth, but with high
}

\section{2 individual tree variability}

3 Andrew Hacket-Pain ${ }^{\mathrm{a}^{*}}$

$4 \quad$ Davide Ascoli

$5 \quad$ Roberta Berretti

6 Maurizio Mencuccini ${ }^{\text {de }}$

$7 \quad$ Renzo Motta $^{f}$

8 Paola Nolag

$9 \quad$ Pietro Piussi ${ }^{\text {h }}$

$10 \quad$ Flavio Ruffinatto

11 Giorgio Vacchiano

a. Department of Geography and Planning, School of Environmental Sciences, University of Liverpool, Liverpool, UK. Andrew.hacket-pain@liverpool.ac.uk * corresponding author

b. DISAFA, University of Turin, Largo Braccini 2, 10095 Grugliasco (TO), Italy davide.ascoli@unina.it

c. DISAFA, University of Turin, Largo Braccini 2, 10095 Grugliasco (TO), Italy. roberta.berretti@unito.it

d. CREAF, c/o Universidad Autonoma de Barcelona, 11 Edificio C, 08290 Cerdanyola, Barcelona, Spain

e. ICREA, Pg. Lluís Companys 23, 08010 Barcelona, Spain. m.mencuccini@creaf.uab.cat

f. DISAFA, University of Turin, Largo Braccini 2, 10095 Grugliasco (TO), Italy. renzo.motta@unito.it

g. Department of Earth and Environmental Sciences, Università degli Studi di Pavia, Pavia, Italy.paola.nola@unipv.it 
h. Retired. Formerly at Dipartimento di Gestione dei Sistemi Agrari, Alimentari e Forestali (GESAAF), University of Florence, Via San Bonaventura 13, I-50144 Firenze, Italy.

i. TeSAF, University of Padova, Viale dell'Università 16, 35020 Legnaro (PD), Italy.

29 flavio.ruffinatto@unipd.it.

30

j. DISAA, Università degli Studi di Milano, via Celoria 2, 20123 Milano, Italy.

31 gvacchiano@gmail.com 
Keywords:

34 Picea abies, tree ring, dendrochronology, mast, super-producer, Paneveggio, growth-reproduction trade-off

36

37

38 Highlights

39

- Cone production is synchronised between trees, but dominated by "super-producers"

40

- Cone and seed production show no long-term temporal trend despite strong regional

42 warming

43

- Radial growth is lower in mast years that coincide with unfavourable climate (cool summer temperature)

46

47

- Growth reductions in mast years are restricted to "super-producers"

48

49

50

51 


\section{Abstract}

53

Tree growth and reproduction are subject to trade-offs in resource allocation. At the same time, they are both influenced by climate. In this study, we combined long records of reproductive effort at the individual- (29 years), population- (41 years) and regional (up to 53 years) scale, and tree ring chronologies, to investigate the effects of climate and reproductive allocation on radial growth in an Alpine Norway spruce forest.

Seed and cone production was highly variable between years (mean individual CV $=1.39$, population $\mathrm{CV}=1.19$ ), but showed high reproductive synchrony between individuals (mean inter-tree correlation $=0.72$ ). No long-term trend in reproductive effort was detected over four decades of observations. At the stand scale, cone production was dominated by a small number of individuals ("super-producers"), who remained dominant over three decades.

Individual tree growth responded positively to summer temperature, but the response to cone production varied between individual trees. Consequently, we found some evidence that mast years were associated with a divergence in growth between high and low cone producing individuals, and a decline in within-population growth synchrony.

At the population level we found limited evidence of a relationship between growth and reproduction. Radial growth was lower than average in some mast years, but not in others. This was partly explained by summer temperature during the year of growth, with growth reductions restricted to mast years that coincided with colder than average summers. Regional mast records and tree ring chronologies provided some support to indicate that our results were consistent in other spruce stands, although the effect of mast years on growth appeared to vary between sites. 
77 Tree ring variation at the individual and population level, and between-tree growth synchrony are

78 influenced by masting, and consequently dendrochronologists should consider both the occurrence

79 of masting and the individual differences in reproductive effort when interpreting tree ring datasets.

80 Our results also indicate that tree ring chronologies contain information to facilitate reconstruction

81 of mast events, which will help address outstanding questions regarding the future response of

82 masting to climate change. 
Tree growth and reproduction are the endogenous processes that drive forest dynamics and tree population demography, along with mortality. Growth is strongly influenced by climate, through control on wood formation processes (Carrer et al., 2017), and through complex effects on resource accumulation and availability (Hayat et al., 2017; Medlyn et al., 2002). Likewise, allocation to reproduction is also strongly influenced by climate, directly via climate cues (Vacchiano et al., 2017) that trigger flowering and affect pollination efficiency (Koenig et al., 2015), and indirectly through the regulation of available resources (Pearse, Koenig and Kelly, 2016; AllenMillard and Richardson, 2017). Growth and reproduction are themselves related through a trade-off for resources (Barringer, Koenig and Knops, 2013; Obeso, 2002), which may itself vary in strength with climate (Sletvold and Agren, 2015; Hacket-Pain, Lageard and Thomas, 2017; Villellas and Garcia, 2018). Consequently, integrating growth and reproduction data should allow a more complete understanding of the tree growth responses to climate, including climate extremes and long-term trends (Davi et al., 2016; Hacket-Pain et al., 2018; Lucas-Borja and Vacchiano, 2018). Internal reserves in mature trees may be expected to buffer against the trade-off between growth and reproduction, but growth reductions in years of high reproductive investment are frequently reported (Barringer, Koenig and Knops, 2013; Hacket-Pain, Lageard and Thomas, 2017; Monks and Kelly, 2006; Selas et al., 2002). Masting species may show particularly strong trade-offs as their reproductive strategy is characterised by highly variable allocation to reproduction (Kelly and Sork, 2002; Mencuccini, Piussi and Sulli, 1995; Pearse, Koenig and Kelly, 2016). Growth reductions in mast years have been reported in studies focused on Norway spruce, a typical masting tree species (Mencuccini and Piussi, 1995; Selas et al., 2002), but other studies have failed to find evidence to support the existence of a trade-off between growth and reproduction in this species (Seifert and Mueller-Starck, 2009). There are various possible explanations for the conflicting reports of this 
trade-off, including challenges in effectively measuring the cost of reproduction (Obeso, 2002), costs being offset by the use of reserves (Mund et al., 2010) or compensatory carbon gain via photosynthesis in the tissues of the developing reproductive organs (Hoch, 2005). Alternatively, allocation to reproduction and growth may be positively correlated with the same climatic variables, so that growth and reproduction may be positively rather than negatively correlated (Despland and Houle, 1997). Additionally, under favourable growing conditions, a reduction in growth associated with investment in reproduction may be weaker or absent; i.e. the strength of the growthreproduction trade-off may depend on stress or resource availability (Barringer, Koenig and Knops, 2013; Berdanier and Clark, 2016; Hacket-Pain, Lageard and Thomas, 2017). In these scenarios, a high investment in reproduction may not translate to a decrease in growth.

Additionally, allocation to reproduction is known to vary between individuals due to canopy position and microenvironmental conditions (Davi et al., 2016; Greene et al., 2002; Brooke et al., 2019), tree age and size (Thomas, 2011; Krouchi, Derridj and Lefevre, 2004), genetic control (Seifert and Mueller-Starck, 2009), or other factors (note that these may not be independent). Consequently, cone production at the stand scale may be dominated by a subset of "super-producers" (Minor and Kobe, 2017; Brooke et al., 2019). Such intraspecific variation in allocation to reproduction may result in variation in the cost of reproduction between individuals during population-wide mast years, so that any growth reductions may be greater in individuals that invest more heavily in reproduction (Patterson and Knapp, 2018). This would be consistent with numerous studies reporting lower growth in female individuals in dioecious species (Obeso, 2002). Furthermore, the cost of driven by individualistic responses to reproduction remains underexplored. 
To investigate how relationships between reproduction, growth and climate vary between individuals, and their interplay at the tree level, we used data from a Norway spruce population in the Italian Alps. Population-level data on reproduction was collected for the period 1971-2012, and 13 individual trees were monitored annually for cone production for 29 years (1983-2012, with no data from 2007). Tree ring samples were collected from these 13 individuals in 2013 . We also use a network of spruce chronologies from the Alps and regional masting records from the MASTREE database (Ascoli et al., 2017a) to test whether our results can be generalised for Alpine spruce forests.

We test the following hypotheses:

1. Seed production is synchronous at the population level, but cone production is dominated

2. Years of high seed production are associated with reduced growth. The trade-off is stronger

3. Growth-reproduction trade-offs are stronger in "super-producers", resulting in reduced growth synchronisation in mast years, and growth divergence between "super-producers" and other trees 


\subsection{Data collection}

Analysis focused on Norway spruce (Picea abies (L.) Karst.) forests located in the upper Travignolo is continental, with mean annual precipitation of $1250-1660 \mathrm{~mm} \cdot \mathrm{year}^{-1}$ and mean annual temperature of $2.7^{\circ} \mathrm{C}$. Spruce seed production has been monitored in Paneveggio since 1962 using seed traps, although data collected prior to 1971 is considered potentially unreliable and was not included in our analysis (Mencuccini, Piussi and Sulli, 1995). Seed traps were deployed in October, and seeds were collected after snowmelt. Following collection, seeds were sorted and tested in germination chambers. Counts of viable, predated and damaged seeds were used to quantify annual reproductive effort.

In the same forest, long-term monitoring of annual reproductive effort by 13 individual trees was conducted 1983-2012. All monitored individuals were located within $70 \mathrm{~m}$ from one another, and individual tree reproduction was quantified by an annual cone count during June. Trees were located at the edge of a gap created in the lower part of the forest (1520 m a.s.I.) for experimental forest management purposes (Piussi, 1988). The stand was uneven aged, but represented by a single canopy structure, with small differences in tree height. Cones were counted each year from the same observation point, providing a consistent indicator of individual and aggregated cone

177 production. Except for 2007, cones were counted annually until 2013, when some trees were windthrown (although only data to 2012 was used this analysis, to match the tree ring data - see below). To extend the stand-level record of reproduction based on the average of the 13 individual trees, a linear regression between annual mean seed count (across seed traps) and mean cone count 
create a 42-year record of population-level reproduction at this site (Figure 1, "cone index"), which consisted of predicted cone counts for the period 1971-1982 and observed cone counts 1983-2012.

In 2013, increment cores were extracted from the 13 individual trees that had been monitored for cone production, by taking two cores per tree at breast height $(1.3 \mathrm{~m})$. Cores were mounted and sanded with progressively finer sandpaper until tree ring boundaries were clearly visible. Tree ring widths were measured using a binocular microscope and LINTAB measuring devices (Rinntech, Heidelberg, Germany) to the nearest $0.01 \mathrm{~mm}$. The accuracy of visual cross-dating and measurements was checked with the COFECHA program (Grissino-Mayer, 2001). Cross-dated series belonging to the same tree were then averaged. Ring width series were detrended using a doubledetrending protocol, first using a modified negative exponential curve to remove the age- or sizerelated trend, and then using a 20-year cubic spline with frequency cut-off of 0.5 to remove trends associated with disturbance and canopy dynamics (Cook and Peters, 1981). The individual tree ring series were pre-whitened to reduce temporal autocorrelation by fitting an autoregressive model, whose optimal order was selected to minimise the Akaike's Information Criterion (AIC) score. A stand ring width index (RWI) chronology was created by averaging the detrended series from the 13 trees. Basal area increment (BAl) was calculated for individual trees using the formula:

Processing of ring width measurements was conducted using the dpIR package in R (Bunn, 2008; R Development Core Team, 2016). Monthly climate data for Paneveggio was extracted from the HISTALP dataset at 5'x5' resolution (Auer et al., 2007), using the histalp package (Zang, 2018). $B A I_{t}=\pi\left(r_{t}^{2}-r_{t-1}^{2}\right)$, where $r$ is the radius of the tree in year $t$. 


\subsection{Individual and population-scale analysis}

209

210

211

212

Trends and patterns of seed and cone production were assessed for Paneveggio using population and individual-tree data (Vacchiano et al., 2018). Synchrony of reproductive effort between individuals was quantified as the mean Pearson product-moment correlation between pairs of individual trees, and variability was assessed using the coefficient of variation (CV). Autocorrelation functions (ACF) were used to test for serial correlation in seed and cone production time-series. We identified mast events when reproductive effort exceed one standard deviation from the long-term mean (LaMontagne and Boutin, 2009). We hypothesised that "super-producers" would dominate overall cone production at the stand scale, either due to larger cone crops in mast years, or more frequent large cone crops (or both). To test this, we defined individual-level "bumper crops" (the individual-tree equivalent of a "mast year") as years when individual tree cone count exceed one standard deviation from the mean cone count from all 13 individuals over whole the study period.

Relationships between reproduction and growth, and climate and growth were assessed using generalised additive models (GAMs). Where GAMs indicated a linear relationship between two variables (estimated degrees of freedom close to 1), we re-fitted using linear regression models. As tree ring data (RWI) was detrended, we also removed long-term trends in the climate data using linear regression. As cone production varied strongly between individuals, analysis was conducted at the individual level, as well as the population-level. Effects of variable reproduction (between years) on between-tree growth synchrony was tested by calculating inter-individual growth variability for each year (using the CV). A higher CV for an individual year indicated greater between-tree growth variability, representing lower growth synchrony. To test for growth divergence between heavy and light cone producers, we created a mean RWI chronology of heavy cone producers, and compared this to a mean RWI chronology of the other trees. We defined heavy cone producers as individual trees with above average cone counts across the whole study period. 
To test the generality of our results from Paneveggio, we analysed other spruce tree ring chronologies from the Alpine region (Italian and Swiss Alps) together with regional records of spruce mast years. Tree ring chronologies from the International Tree Ring Data Bank (ITRDB) (insert reference for the chronologies SWIT332, 279, 256 and 329 - we cannot do this at the moment at the ITRDB is unavailable during the US Government shutdown - this will need to be added later) were combined with existing and new tree-ring chronologies from the Italian Alps (Table 2).

Detrending and chronology building followed the protocol used for the Paneveggio site. Regional masting chronologies were developed for Switzerland (NUTS-1 region $\mathrm{CHO}$ ), Slovenia (SIO) and Northwest Italy (ITC) using the MASTREE database (Ascoli et al., 2017a). In this dataset, annual seed production is summarised in the database using five ordinal classes. Where multiple records existed in a given year for the same NUTS-1 region, the modal value was used, following the method of Vacchiano et al. (2017). In this regional-scale analysis, and due to a limited sample size (number of years), ordinal data was then reclassified to a binary scale, comprising mast years (category 4 and 5) and non-mast years (category 1-3) (Ascoli et al., 2017b). The cruts package (Taylor and Parida, 2016) was used to create NUTS-1 regional climate series from the CRU TS 3.23 gridded dataset (Harris et al., 2014), as region-wide means of individual-cell monthly values. 


\subsection{Seed production: variability between years and individuals}

Cone production was highly variable at Paneveggio, both between individuals and between years. Individual tree coefficient of variation $\left(\mathrm{CV}_{\mathrm{i}}\right)$ for cone counts across the period 1983-2012 varied between 1.11 and 1.97 (mean = 1.39), and the CV of the mean population cone count chronology (population-level $\mathrm{CV}, \mathrm{CV}_{\mathrm{p}}$ ) was 1.19 (1983-2012). The $\mathrm{CV}_{\mathrm{p}}$ for seed trap data 1971-2012 was 1.28. Cone production and seed counts had significant negative autocorrelation at lag -1 year (Supp. Figure 2). The extended 1971-2012 cone index, developed using a combination of seed trap data and mean cone counts, indicated the presence of large mast years in 1976, 1981 and 1995 (cone index $>2$ standard deviations from the mean), with additional mast years (>1 SD) in 1985 and 1988. The overall distribution of seed production during the period 1971-2012 was a continuous reserve Jshaped distribution (Figure 1D and Supp. Figure 3). A Hartigans' dip-test indicated no evidence of multimodality ( $p>>0.05$ for seed count, cone count and combined cone index). In 1997 and 2008 no cones were counted on any of the 13 individuals, but in every other year cones were observed on at least one individual. The seed-trap datasets recorded some seed fall in every year - i.e. there were no years with zero recorded spruce seed production. The full 1971-2012 cone index chronology showed no long-term linear trend (regression of seed production versus year, $p>0.05$ ), and this was also the case individually for the seed-trap dataset (1971-1994) and the mean cone-count dataset (1983-2012) (Supp. Figure 4). For the individual tree cone-count series (1983-2012), linear trends through time were also insignificant for all trees (Supp. Figure 4).

Cone production varied strongly between the 13 individual trees, and most cones were produced by a small proportion of individuals (Figure 1). The highest producing individual (ID_01) produced 26.3\% of all produced cones (1983-2012), x2.5 the next highest producer. The lowest producer was responsible for only $1.7 \%$ of total cones. Bumper cone crops associated with individual trees were 
generally quite rare (Figure 1A). Most tree produced between one and four such bumper crops over the 29 years of observation, while two individuals failed to produce a single bumper crops. In contrast, one individual (ID_01) produced 13 individual bumper crops, equivalent to almost one every two years on average. Total cone production (1983-2012) was correlated with tree diameter $(r=0.539, p=0.057$, Supp. Figure 5), and there was a significant positive correlation with Basal Area Increment (BAI) 1983-2012 (Supp. Figure 6). However, with only thirteen trees these relationships were difficult to quantify, and both relationships were dependent on the inclusion of the highest producing individual (ID_01). Correlations were insignificant between total cone production (19832012) and tree age (estimated by counting the total number of measured tree rings).

Heavy cone producers remained heavy producers over at least three decades (Figure 1). For example, excluding the two years when no individuals produced any cones, the highest producing tree (ID_01) was the top-ranked producer 19 times $(19 / 28=67.9 \%$, highest producer in $2 / 3$ of individual years), and the five individuals with the highest mean rank took $67 \%$ of the available annual top five ranking positions over 28 years. With 13 individual trees, an individual could expect to be in the top five $38 \%$ of all years if ranking was random. In contrast, the lowest ranking tree (ID_10) was in the top five on only three occasions, and the five lowest ranking individuals took only $25 \%$ of the available top five positions.

While highly variable between years and between individuals, cone production was synchronised between trees (Figure 1). Mean inter-tree correlation was $0.72(\min =0.33, \max =0.91$, median $=$ 0.73). Cone and seed production at Paneveggio was also strongly synchronised with other Alpine masting chronologies for spruce. For example, high cone or seed counts were reported from spruce in 1995 in many of the records contained in the MASTREE database (Ascoli et al. 2017b). Cone index was positively correlated with neighbouring regional masting chronologies developed for cone and seed counts for $\mathrm{CHO}$ (Switzerland) (rho= $0.71, p<0.001, n=30$ ), ITC (NW Italy) ( $r h=0.44, p=0.129$, $n=12)$ and SIO (Slovenia) $(r h=0.13, p=0.049, n=30)$. 
Table 1. Site and chronologies statistics for all sites. All statistics are reported for residual prewhitened chronology. EPS $=$ Expressed Population Signal, rbar $=$ inter-series

correlation, $\mathrm{SNR}=$ signal-to-noise ratio, $\mathrm{AC}_{1}=$ first order autocorrelation, $\mathrm{MS}=$ mean sensitivity

\begin{tabular}{|c|c|c|c|c|c|c|c|c|c|c|c|c|c|}
\hline Site & Lat & Lon & Elev & Period* & Length* & $\mathbf{N}^{\circ}$ trees & EPS & rbar & SNR & $\begin{array}{l}\text { Mean } \\
\text { (RWI) }\end{array}$ & $\begin{array}{c}\text { SD } \\
\text { (RWI) }\end{array}$ & $\begin{array}{c}\mathrm{AC}_{1} \\
\text { (RWI) }\end{array}$ & MS \\
\hline PAN & 46.18 & 11.45 & 1520 & $1813-2012$ & 200 & 13 & 0.893 & 0.446 & 8.34 & 0.988 & 0.121 & -0.072 & 0.122 \\
\hline PAN (study period) & 46.18 & 11.45 & 1520 & $1971-2012$ & 42 & 13 & 0.910 & 0.436 & 10.06 & 0.998 & 0.075 & -0.065 & 0.085 \\
\hline SWIT332 & 46.46 & 9.18 & 1660 & $1842-2005$ & 164 & 10 & 0.930 & 0.449 & 13.34 & 0.998 & 0.098 & 0.050 & 0.110 \\
\hline SWIT279 & 46.59 & 7.98 & 1850 & $1689-2011$ & 323 & 25 & 0.924 & 0.455 & 12.21 & 0.988 & 0.121 & 0.023 & 0.131 \\
\hline SWIT256 & 46.30 & 7.72 & 900 & $1882-2005$ & 124 & 12 & 0.941 & 0.527 & 15.892 & 0.989 & 0.218 & -0.001 & 0.260 \\
\hline SWIT329 & 46.27 & 7.03 & 1440 & $1907-2005$ & 99 & 16 & 0.948 & 0.405 & 18.239 & 0.998 & 0.114 & -0.191 & 0.146 \\
\hline BREP & 46.19 & 10.85 & 1550 & $1851-2010$ & 160 & 20 & 0.903 & 0.353 & 9.341 & 0.994 & 0.090 & -0.074 & 0.100 \\
\hline MASP & 46.27 & 9.58 & 1150 & $1897-2013$ & 117 & 31 & 0.927 & 0.375 & 12.693 & 0.999 & 0.113 & -0.037 & 0.132 \\
\hline SALP & 45.05 & 6.90 & 1800 & $1806-2017$ & 212 & 25 & 0.823 & 0.284 & 4.649 & 0.997 & 0.112 & -0.081 & 0.120 \\
\hline VENP & 46.66 & 10.52 & 1500 & $1880-2017$ & 138 & 10 & 0.873 & 0.460 & 6.868 & 0.990 & 0.145 & -0.076 & 0.177 \\
\hline VIEP & 45.64 & 7.27 & 1500 & $1842-2016$ & 175 & 12 & 0.882 & 0.405 & 7.468 & 0.992 & 0.100 & -0.136 & 0.117 \\
\hline
\end{tabular}

$310 *$ Note that period and length are taken from the residual prewhitened chronology, and therefore do not represent the full period of the raw chronology. 


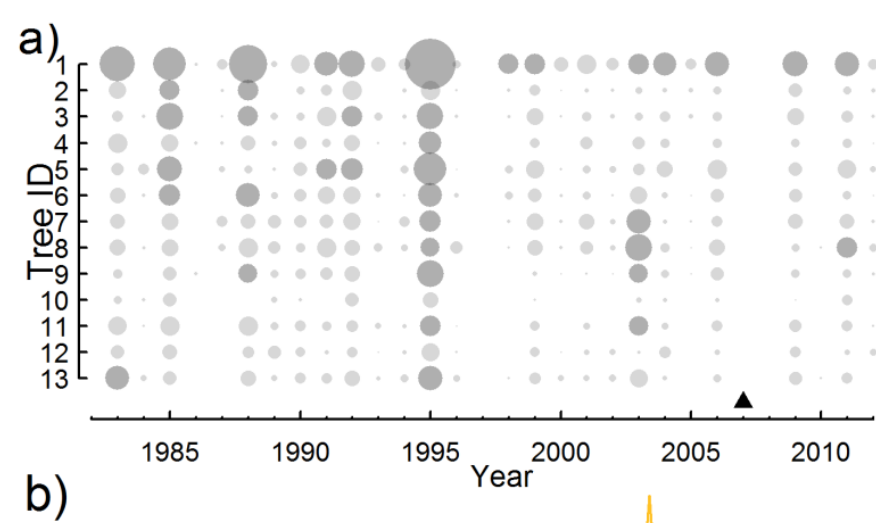

b)

\subsection{Stand-scale growth-reproduction trade-offs}
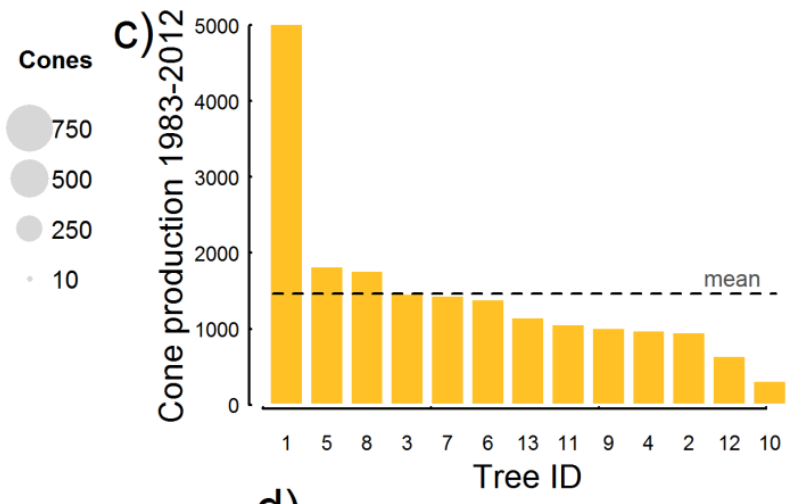

d)

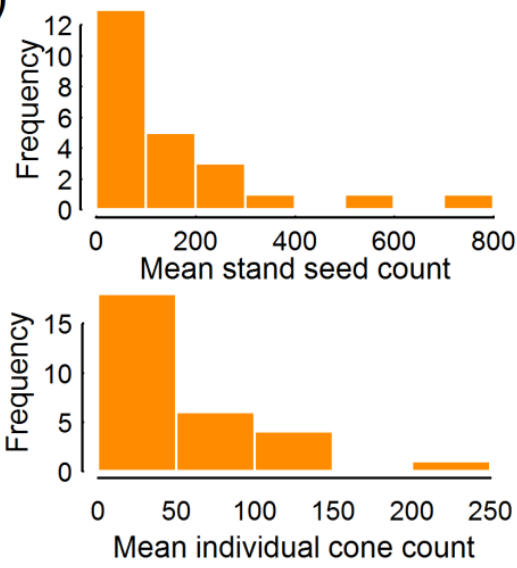

Figure 1. Cone and seed production at Paneveggio a) Individual tree cone counts 1983-2012. Symbol size is proportional

to individual cone count, and shading indicates a bumper cone crop (individual cone production greater than the mean

of all trees across the study period). Triangle indicates year with no data (2007). b) Individual tree cone counts (yellow) and the stand mean (dark brown) for the period 1983-2012, and predicted stand mean cone count for the period 19711982 (light brown). Dashed and dotted lines indicate +1 and +2 standard deviations from the mean, the definitions of mast and large mast year respectively. Stand-level seed counts (orange, 1971-1994). Observed and predicted cone counts are combined for the period 1971-2012 ("Cone index"), and are used in the rest of the analysis. c) Total cone production over the study period for the 13 monitored trees. The dashed line indicates the mean cone production. d) Frequency plots for stand-level seed count (1971-1994) and mean individual cone count (1983-2012).

The relationship between stand-level ring width index (RWI) (mean of the 13 trees) and the combined stand cone index was weak and insignificant $(r=-0.128, p=0.424)$. This was consistent when analysed using the seed-count data only (1971-1994, $r=-0.127, p=0.555)$, and the cone count data only $(1982-2012, r=-0.081$, $p=0.676$ ). Relationships were also insignificant when tested using GAMs (i.e. allowing for non-linear 
relationships, results not shown). Some mast years were associated with low growth (e.g. 1981, 1995), but the large mast year in 1976 was associated with above average growth (Figure 2). Summer temperature (mean of May-July) was positively correlated with RWI for the period 1971-2012, $(r=0.313, p=0.044$; see also Figure 3D), and appeared to influence the response of RWI to cone index. In warm summers (summer temperature $>1971-2012$ mean), there was no significant response to reproduction $(r=0.169, p=0.48)$, but in cool summers cone index and RWI were negatively- correlated $(r=-0.471, p=0.031)$ (Figure 2). This indicated that a growth-reproduction trade-off was restricted to cool summers, where cone index explained $22 \%$ of variation in RWI (but $<2 \%$ in analysis including all years, Figure $2 \mathrm{~B}$ ). However, with only five mast years in the 42-year record, and as the significant relationship in cool summers is dependent on the inclusion of the two large mast years in 1981 and 1995, this result should be treated with caution.

A)
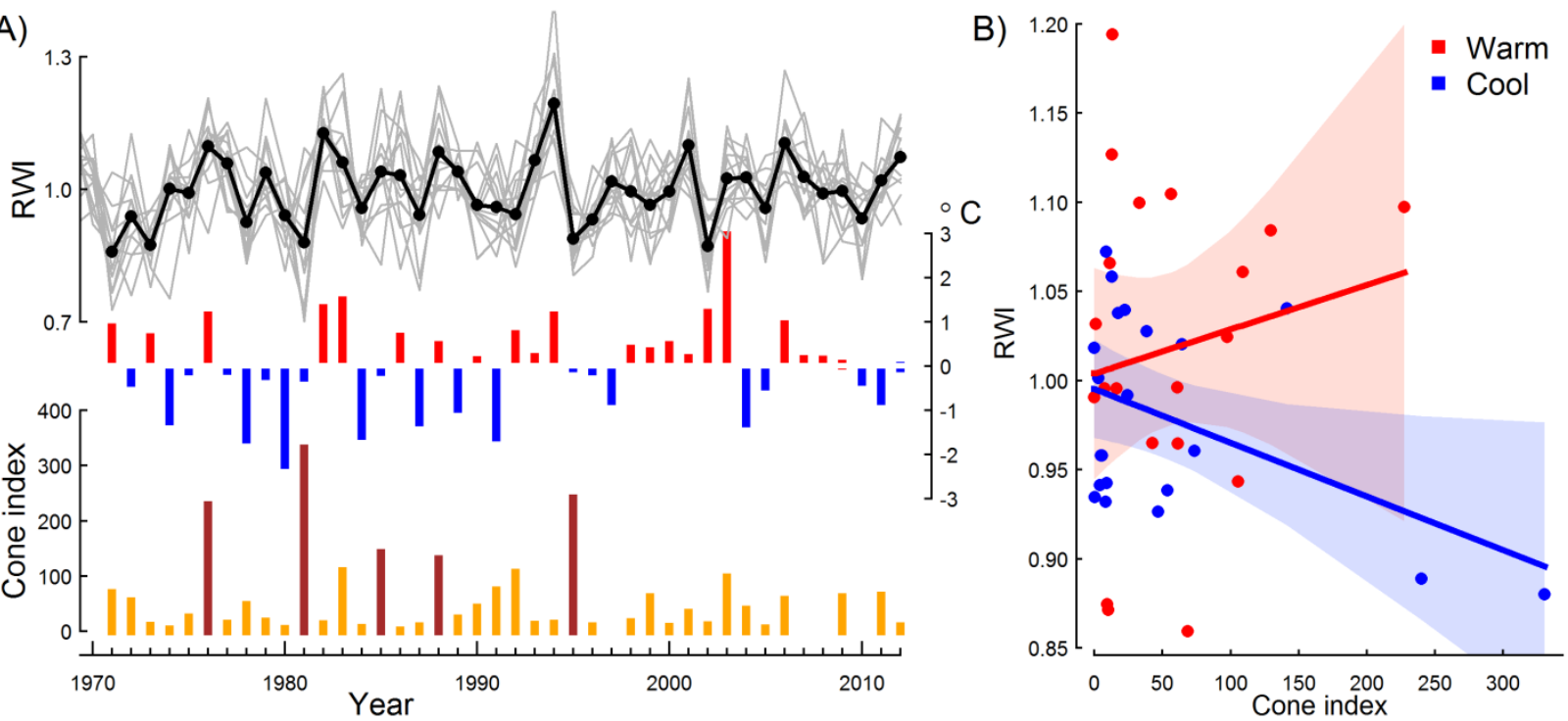

Figure 2. A) Time series with individual and mean stand RWI chronologies, May-July temperature anomalies and cone index. For temperature, red and blue bars indicate positive and negative temperature anomalies respectively. Mast years (cone index greater than one standard deviation from the mean) are plotted in dark brown. Note that the temperature anomalies are for detrended summer temperature (i.e. the linear trend in temperature is removed). B) The linear regressions for RWI cone index for cold (blue) and warm (red) summers (1971-2012), including 95\% confidence intervals. 
347 To test the generality of these results, growth responses to regional mast years (MASTREE database) were

348 tested for a network of Alpine spruce chronologies. Some sites showed lower growth in regional mast years, 349 particularly those in northwest Italy (ITC: MASP, SALP and VIEP), and also the Swiss site SWIT256, but the 350 growth reduction in mast years were small and marginally significant for only one site (VIEP, $p=0.048)$ (Supp.

351 Figure 7). The lack of a strong and significant relationship between RWI and masting was therefore 352 consistent with the results from Paneveggio. Short overlapping time series made it difficult to test whether 353 growth reductions were stronger in colder summers, as found at Paneveggio (Supp. Figure 8).

\section{$355 \quad 3.3$ Individualistic growth responses to climate and reproduction}

356 The climate response of individuals showed some variation, but warmer summers were associated with high 357 growth (Figure 3D). However, the growth response of individuals to reproduction showed more variation, 358 both when tested against the corresponding individual tree cone counts (1983-2012, Figure 3B), and when 359 tested against the stand-scale cone index (1971-2012, Figure 3C). However, the relationship was significant 360 in only one individual (note that this was an individual with above-average cone production, but not ID_01, 361 the outstanding super-producer). High investment in cone production (at an individual- and stand-level) was 362 associated with lower growth in the individuals with higher cone productivity (Figure 3). Responses of 363 growth to mast years were close to zero or even positive in individuals with low cone productivity (albeit 364 non-significant). For example, in heavier cone producers, the growth reductions in the heaviest stand-scale mast years were approximately equivalent in magnitude to those associated with coolest summers (Figure 3663 C and 3D). In contrast, the lightest cone producers showed positive growth responses in these years, 367 equivalent in magnitude to the growth increase associated with a warm summer (Figure 3C and 3D). 


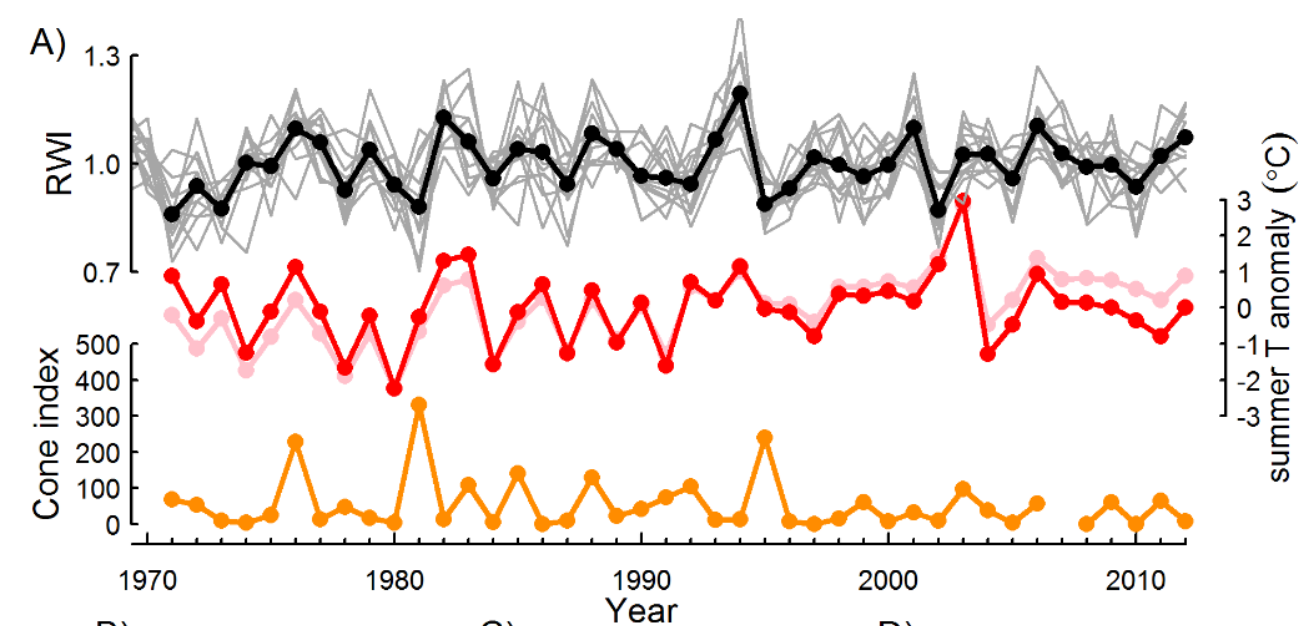

B)

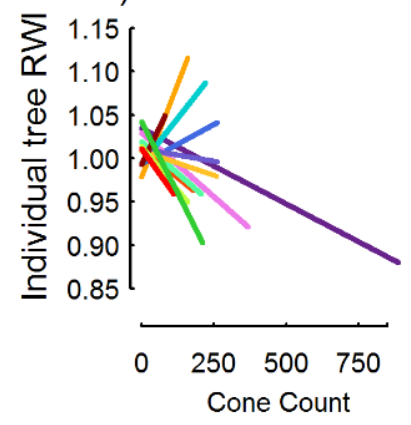

C)

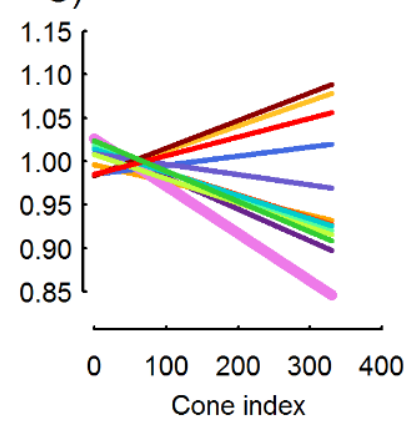

D)

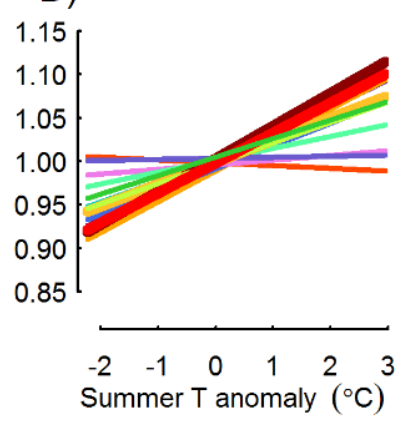

Figure 3. A) Time series with individual (thin lines) and stand-level (thick lines) RWI chronologies, summer temperature

and cone index. The pink line represents raw summer temperature data, while the red line is linearly detrended data.

372 The detrended data is used for the regression analysis. For B-D, only the regression lines are plotted. Each line

373 represents the regression between individual tree RWI and B) corresponding individual tree cone counts (1982-2012),

C) stand-scale cone index (1971-2012) D) summer temperature (detrended anomaly, 1971-2012). Thick lines indicate significant models. Line colour represents the individual tree ranking for total 1983-2012 cone count; heavy cone producers are purple/blue, and light producers are orange/red.

Overall, between-tree growth synchrony was high (rbar $=0.44$, Table 1 , and see also Figure $3 \mathrm{~A}$ ), representing a strong coherence in growth between years. However there were differences in synchrony between years; in other words, in some years individuals had very similar growth while in other years growth diverged between individuals (Figure 3A). The year with the highest stand-scale reproductive effort corresponded to the year with the highest between-individual growth CV (lowest growth synchrony) (1981, see Supp. Figure 9). There was a significant relationship between cone index and growth CV (Supp. Figure 9), suggesting that 
high reproductive effort (at the stand scale) was associated with a decline in growth synchrony between individuals. However, the significance of the relationship was dependent on the inclusion of 1981, the year with highest cone index and between-tree growth CV. Without 1981, the relationship between-tree growth

388 CV and cone index became insignificant. A similarly mixed picture emerged from analysis of between389 individual growth CV for other regional chronologies (Supp. Figure 10). Between-tree growth synchrony 390 decreased in mast years at some sites (e.g. VIEP, SWIT279) although this was never statistically significant 391 and sample size was always low.

393 We also compared the RWI of heavy producers and other trees, to test whether mast years were associated 394 with a growth divergence $\left(\mathrm{RWI}_{\text {diff }}=\mathrm{RWI} \mathrm{I}_{\text {heavy }}-\mathrm{RW} \mathrm{l}_{\text {light }}\right)$. Heavy producers were defined as individuals with 395 greater than average cone production 1983-2012 (Figure 1c). Overall the correlation between RWI 396 timeseries of heavy and other trees was high $(r=0.81, p<0.001)$ However, $R W I_{\text {diff }}$ varied according to stand cone index. The relationship between $\mathrm{RWI}_{\text {diff }}$ and cone index appeared to be asymmetric, but in mast years heavy producers had lower growth relative to light producers (Figure 4). The difference was largest in the heaviest mast years (Figure 4). The relationship was even stronger if $\mathrm{RWI}_{\text {light }}$ was calculated for the equivalent three lightest producers, rather than for all other trees (results not shown). 


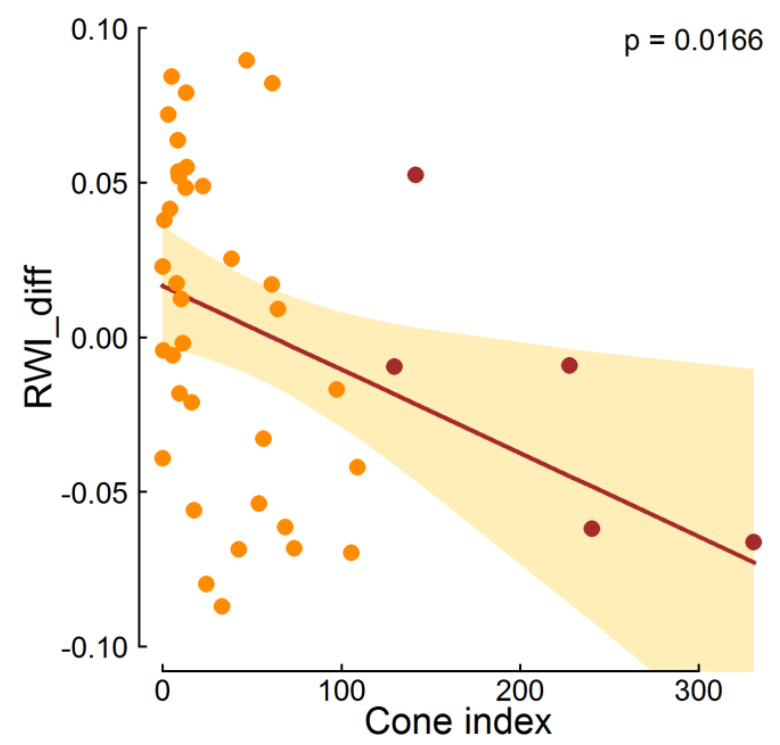

402

403 Figure 4. Relationship between $\mathrm{RWI}_{\text {diff }}$ and stand-level cone index (1971-2012), with a 95\% confidence interval.

404 Negative values indicate that heavy producing trees had lower growth than other trees. Brown points represent mast 405 years at the stand scale.

406 


\subsection{Characteristics of cone production}

411 Cone production at Paneveggio showed characteristics associated with masting. The stand-level $\mathrm{CV}_{\mathrm{p}}$ for cone 412 production was almost identical to that reported by Selas et al. (2002) for Norway spruce in Norway (1.20), 413 and consistent with other reported values for spruce species and other masting species (Herrera et al., 1998; 414 Koenig and Knops, 2000; Lamontagne and Boutin, 2007). In the heaviest mast years, cone index at the stand 415 scale was six times greater than the long-term mean, representing a substantial resource investment. At the 416 individual tree scale the contrast was even more extreme. In 1995 tree ID_01 produced 18 times more cones 417 that the mean cone production of all trees 1982-2012, and this individual was responsible for $26 \%$ of all the 418 cones produced over the study period (by 13 individuals). Various factors may explain such individual 419 variability in reproductive output, including tree age, size, microenvironmental conditions, resource 420 availability, and genetics (Davi et al., 2016; Greene et al., 2002; Seifert and Mueller-Starck, 2009; Thomas, 421 2011; Brooke et al., 2019), although with individual-tree data for only 13 trees, it was not possible to identify 422 the factors controlling long-term cone productivity, or robustly test scaling with tree size. However, our data 423 hinted that high cone production was associated with larger, faster growing trees. Notably, heavy cone producers retained their ranking over three decades. For example, the highest overall cone producer (ID_01) was the heaviest individual producer in two thirds of all years, consistent with the definition of "superproducer" suggested by Minor and Kobe (2017). Previous studies have also indicated that the relative reproductive performance of individual trees can be maintained over multiple years, but have relied on shorter datasets where long-term trends are difficult to identify (Healy, Lewis and Boose, 1999; Krouchi, Derridj and Lefevre, 2004; Linhart and Mitton, 1985).

While variable between years, reproduction was remarkably synchronised between trees $(r=0.72)$, with all 432 trees located within $70 \mathrm{~m}$ from one another. Synchrony of seed production declines with distance (Koenig 433 and Knops, 2000), although not significantly at local scales (Lamontagne and Boutin, 2007). However, the 
observed between-tree synchrony in cone counts was higher than that reported by LaMontagne and Boutin

435 (2007) for Picea glauca, and represents a highly synchronised variation in resource allocation at the stand

436 scale. Previous studies indicate that this synchronisation is also strong between Alpine spruce stands at local

437 scales (MencucciniPiussi and Sulli, 1995), and under appropriate regional climate conditions, synchronisation

438 between populations can extend over larger spatial scales (Ascoli et al., 2017b). Such synchronisation of

439 cone production can have cascading effects on local communities, starting with the population dynamics of

440 seed predators (Bogdziewicz, Zwolak and Crone, 2016) and extending to pulsed regeneration patterns,

441 interaction with herbivores, and cascading trophic interactions (Ostfeld and Keesing, 2000).

442

443 The long-term response of tree reproduction to climate change will be a key factor determining the

444 resilience of forest ecosystems (Caignard et al., 2017; Davi et al., 2016), but the response of masting to 445 ongoing climate change is uncertain (Ascoli et al., 2017b; Pearse, Koenig and Kelly, 2016; Pearse,

446 LaMontagne and Koenig, 2017). Despite their value in addressing how masting will respond to future

447 environmental change, few long-term records of seed production exist, and have revealed contrasting

448 trends. Allen et al. (2014) found a significant increase in seed production in Nothofagus, particularly at high

449 elevations, and similar increases in seed production have been reported for other genera (Caignard et al.,

450 2017; Overgaard, Gemmel and Karlsson, 2007). However, in a large study incorporating over 1000 time-

451 series of annual seed production, Pearse et al. (2017) found an overall decrease in seed production since

452 1900. In our study, no significant change in seed production was detected in either a 30-year record of cone

453 production for individual trees, or a stand-level record of seed production that extended over four decades

454 (1971-2012) (Supp. Figure 4). Summer temperatures increased significantly over this period. However, our

455 long-term dataset highlighted the challenges of detecting long-term changes in tree masting. Even with four

456 decades of data, we observed only three large mast events $(1976,1981,1995)$, which together accounted

457 for $34 \%$ of all seed production despite accounting for only $7 \%$ of all monitored years. When such rare events

458 dominate overall seed production, detecting trends in response to climate change is challenging (Vacchiano

459 et al., 2018). 
The relationship between reproductive effort and tree growth was variable. At the stand scale, mast years were not consistently associated with reduced growth, and we found similar results in a network of Alpine spruce chronologies. At Paneveggio, this generally low sensitivity of growth to investment in reproduction may be related to the generally favourable growing conditions. Paneveggio is a mesic site for spruce, with relatively high annual increment (typically $8-10 \mathrm{~m}^{3} \mathrm{ha}^{-1} \mathrm{y}^{-1}$ ). Furthermore, the timing of investment in the maturation of cones (including lignification) is likely timed after the main phase of radial growth in early summer (Deslauriers et al., 2008), which may minimise a direct trace-off for resources between radial growth and reproduction. We found evidence that in climatically unfavourable years (cool summers), investment in reproduction was associated with reduced growth; this can be interpreted as a variation in trade-off strength with climate (Hacket-Pain, Lageard and Thomas, 2017; Sletvold and Agren, 2015; Villellas and Garcia, 2018), which can explain the generally weak relationships between growth and masting. We suggest that the population-level insensitivity of growth to masting in warm summers observed at Paneveggio may have resulted from increased resource assimilation during these favourable conditions, reducing any trade-off between competing resource sinks. In an earlier study in the same forests, Mencuccini and Piussi (1995) demonstrated that the negative relationship between growth and seed production was stronger at higher elevations (lower temperatures), supporting our findings for variation 478 between years (Figure 2). Consequently, future environmental changes which favour growth may result in relaxation of growth-reproduction trade-offs in high elevation and temperature limited spruce populations, although this remains to be tested.

\subsection{Synchronisation of growth within populations: influence of climate and reproduction} previously been reported from other high elevation spruce stands across the Alps (Castagneri et al., 2014). 
relationships in cone super-producers (Figure 3b). In contrast, the response of growth to reproduction was not consistent between individuals. Variation in trade-off strength between individuals was partly dependent on their long-term cone productivity, such that growth reductions in association with high cone production were generally limited to the heavy cone producers. This is consistent with the findings of Patterson \& Knapp (2018) in longleaf pine forests in southeast U.S.A. Consequently, the individualist growth response to individual cone production (Figure 3B), and to population-level mast years (Figure 3C), created increased growth variance in mast years - i.e. less synchronised growth. However, this was not a strong trend, and we did not find consistent results in the regional network of spruce tree ring chronologies.

As heavy cone producers tended to exhibit lower growth in mast years relative to light cone producers, mast years were associated with growth divergences between heavy and light producers (Figure 4). The divergence increased in strength with increased reproductive effort. This result contrasts with Zywiec and Zielonka (2013), who reported no difference in growth between high and low producers in Sorbus aucuparia in mast years. However, our results are consistent with numerous reports of growth differences between male and female individuals in dioecious species (Obeso, 2002), where higher reproductive investment by females is associated with lower growth rates than in males. As the individual investment in reproduction was consistent over time (both in absolute cone numbers, and in ranking relative to other individuals), the growth divergence in mast years between heavy and light cone producers was also consistent and extended beyond the period of individual tree cone counts (i.e. 1971-1982, the period with stand-level seed counts only). This indicated that over multiple decades, trees that invested heavily in reproduction showed a reduction in growth relative to trees with low investment in reproduction in mast years. However, BAI 19832012 was positively correlated with total cone production over this period (Supp. Figure 6), indicating that long-term high investment in reproduction was not associated with lower growth rates over the study period. If reproductive output is at least partly controlled by genes, it is still unexplained how poor producers are maintained in the population over multiple generations, particularly when our results indicate that high investment in reproduction is not associated with a long-term trade-off with growth. Note that in this study, 
the 13 trees were growing on a fertile site, on the edge of long-existing canopy gap, and maintained high growth rates over the study period; light cone producers were not suppressed or growing in marginal environments.

\subsection{Resource switching and implications for understanding masting}

517 At the population level, we found mixed evidence that increased investment in reproduction resulted in a 518 trade-off with growth; some mast years were associated with reduced growth, but not all. In contrast, Selas 519 et al. (2002) reported stronger effects of seed production on growth in spruce (seed production explained $52042 \%$ of variation in ring width), and Mencuccini and Piussi (1995) found a negative relationship between ring width and seed production in spruce stands from our study area. In our study, cone index explained $22 \%$ of variation in RWI in years with cool summers, but $<2 \%$ in analysis including all years, Figure $2 \mathrm{~B})$. Other studies have also reported a lack of evidence to support a trade-off between tree growth and reproduction (Zywiec and Zielonka, 2013), including in spruce (Seifert and Mueller-Starck, 2009). Monks and Kelly (2006) argue that evidence of resource switching is the most important evidence that masting results from selection for highly variable seed production, and not simply a response to climate (e.g. resource matching) (see also Kelly and Sork, 2002). Our results imply that resource switching was only required during years of unfavourable resource assimilation, but during more favourable conditions growth rate could be maintained even with the additional demands of developing cones. Furthermore, analysis at the individual level demonstrated that cone super-producers did show a reduction in growth in mast years. Consequently, population-level growth chronologies may mask evidence of switching (Patterson and Knapp, 2018), and where possible, evidence of

\subsection{Implications for reconstructing mast years}

535 Multi-decade records of masting are rare (Ascoli et al., 2017a; Kelly and Sork, 2002; PearseLaMontagne and 536 Koenig, 2017), but have revealed important insights into the drivers of changes in masting in response to recent environmental change (Allen et al., 2014; Ascoli et al., 2017b; Pearse, LaMontagne and Koenig, 2017). 
538 Where such long observational records do not exist, reconstructions of mast years using tree ring chronologies may facilitate improved understanding of the response of masting to long-term environmental change, and cascading impacts of these changes on forest ecosystems more generally (Ostfeld and Keesing,

541 2000). For example, Drobyshev (2014) used a multi-century reconstruction of beech mast events in Sweden

542 to demonstrate that decadal changes in mast frequency were not linked to changes in nitrogen deposition

543 (as proposed by Overgaard et al. 2007). However, our results indicate that not all mast years are associated 544 with a reduction in growth (Figure 2), with significant growth reductions limited to years with unfavourable 545 climate (see Hacket-Pain et al. 2017 for similar findings for Fagus sy/vatica). In this case, negative pointer 546 years in ring width series may not be enough to identify all mast years, even if combined with historical 547 climate data for the known climate cues of mast years (the method of Drobyshev et al. 2014). A more 548 complete integration of climate data and tree rings may be required, accounting for factors that influence 549 the sensitivity of ring width to masting events, but mast years that coincided with climatically favourable 550 years may ultimately be harder to detect. However, other tree ring parameters may also provide information 551 on masting. For example, Han et al. (2016) reported small differences in $\delta^{13} \mathrm{C}$ in tree rings associated with 552 mast years in Fagus crenata, and Rodríguez-Ramírez et al. (2018) showed potential for mast year 553 reconstruction based on wood anatomical traits. Additionally, our results indicate that the individualist 554 responses of trees to masting may also prove useful in identifying mast years using individual tree ring data. 555 For example, increased between-tree growth variability may be useful for identifying mast years, and 556 requires no additional information on the sampled trees. This may be a useful source of information to 557 identify mast years (particularly heavy mast years) (Figure 4), and contribute to a "toolbox" of useful 558 indicators for tree-ring based reconstruction of mast years. 
560 Acknowledgements:

561 We acknowledge Chiara Masetti, Sandro Brugnoli, Gipo Gandolfo, Enrico Cavada, Illario Cavada and Alberto 562 Pierguidi for involvement in data collection over many decades. We also acknowledge the Amministrazione 563 Foreste Demaniali Provincia Autonoma Trento. We gratefully acknowledge Prof. Alessandra Zanzi Sulli, who 564 was closely involved in the establishment of the long-term monitoring programme in Paneveggio. We are 565 grateful those who contributed ITRDB datasets which were utilised in this study. We thank two anonymous 566 reviewers whose comments substantially improved the manuscript. 
567 Supplementary Figures

568

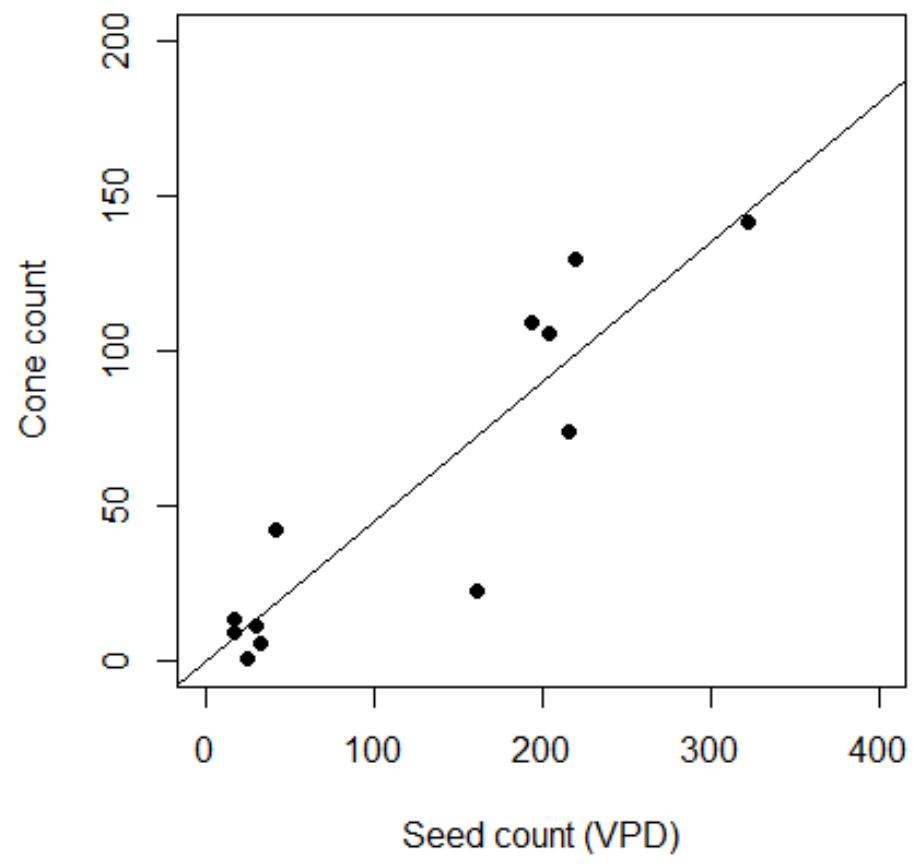

569

570 Supp. Figure 1. Relationship between mean stand cone counts and mean seed count for Paneveggio (VPD,

571 sum of viable, predated, damaged seeds), 1983-1994. $R^{2}=0.82, p<0.001$.

572 


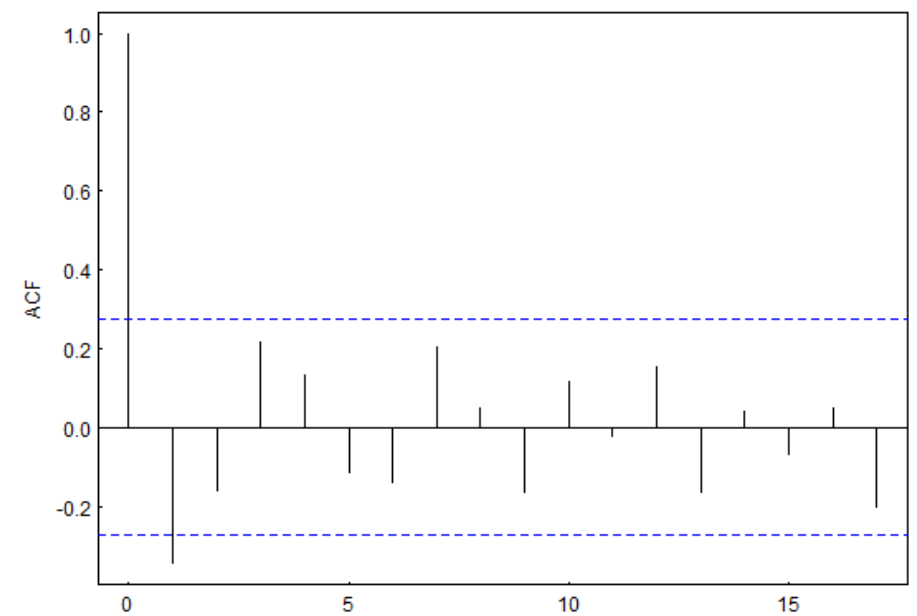

574

Lag

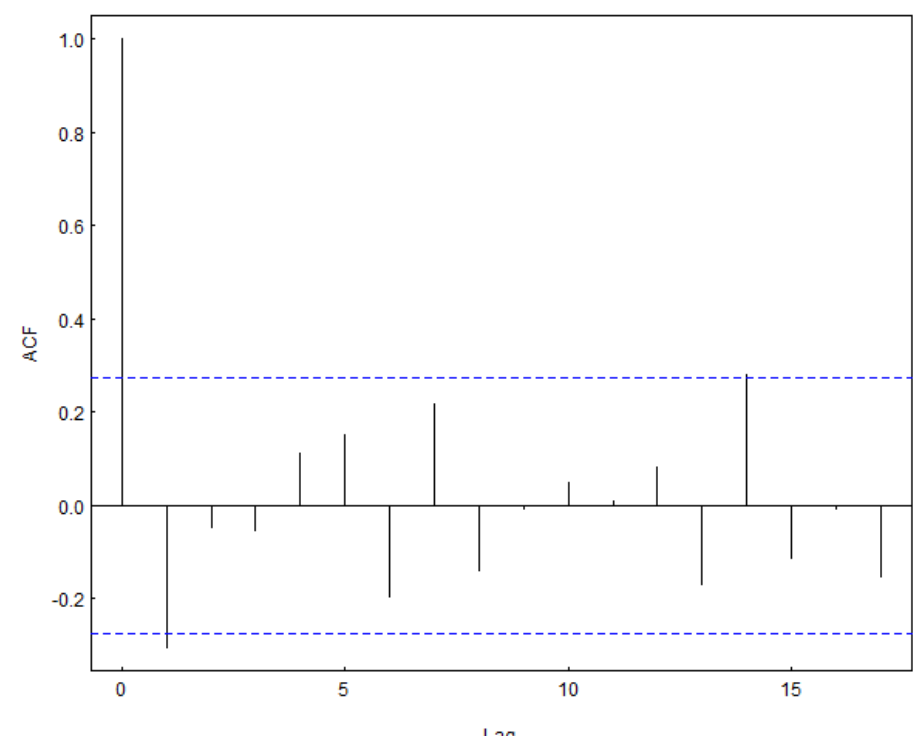

575

576 Supp. Figure 2. Autocorrelation functions for cone production (1982-2012) (top panel) and cone index 577 (1971-2012) (bottom panel)

578 
Histogram of Seed Counts (1971-1994)

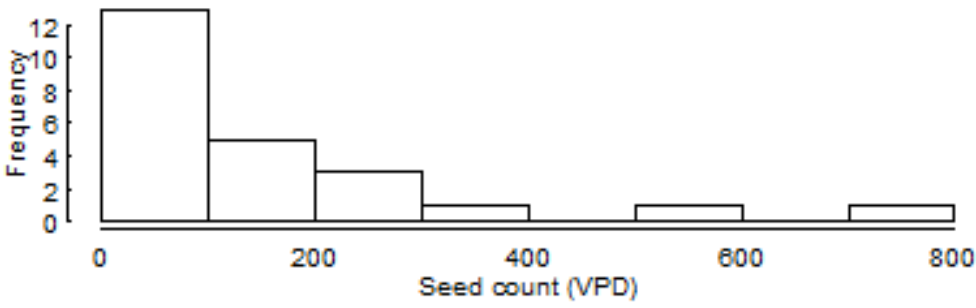

Histogram of Cone Counts (1983-2012)

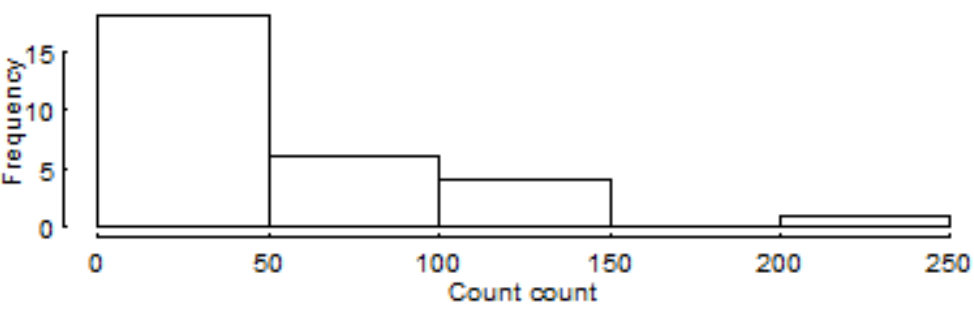

Histogram of Cone index (1971-2012)

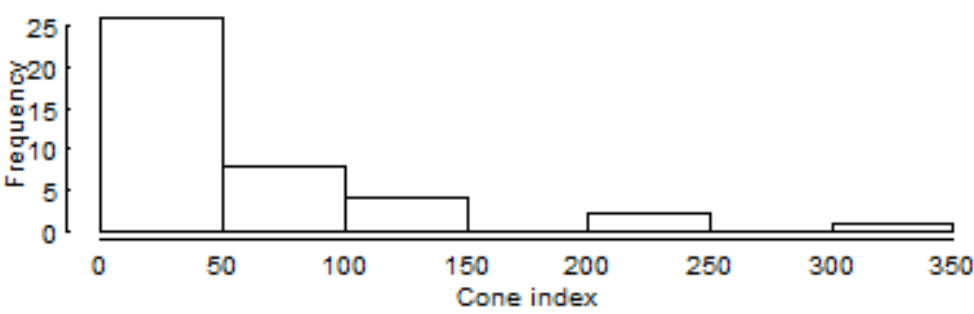

579

580 Supp. Figure 3. Distributions of measures of seed and cone production 581 

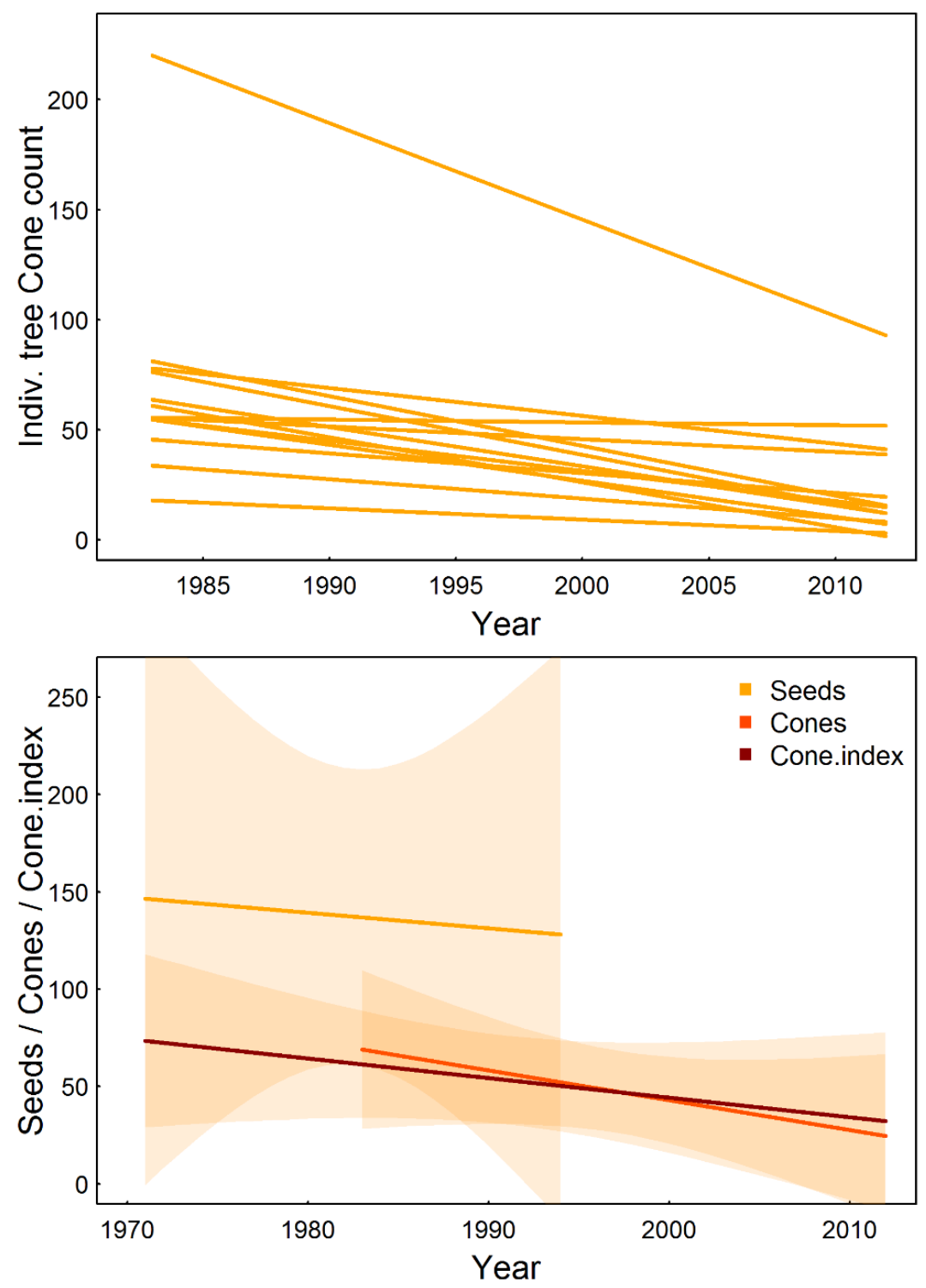

584 Supp. Figure 4. Linear trends in cone counts for 13 individual trees. All trends were insignificant at 95\%

585 confidence level (top panel). Linear trends in stand-level measures of seed/cone production. All trends were 586 insignificant at 95\% confidence level (bottom panel). 


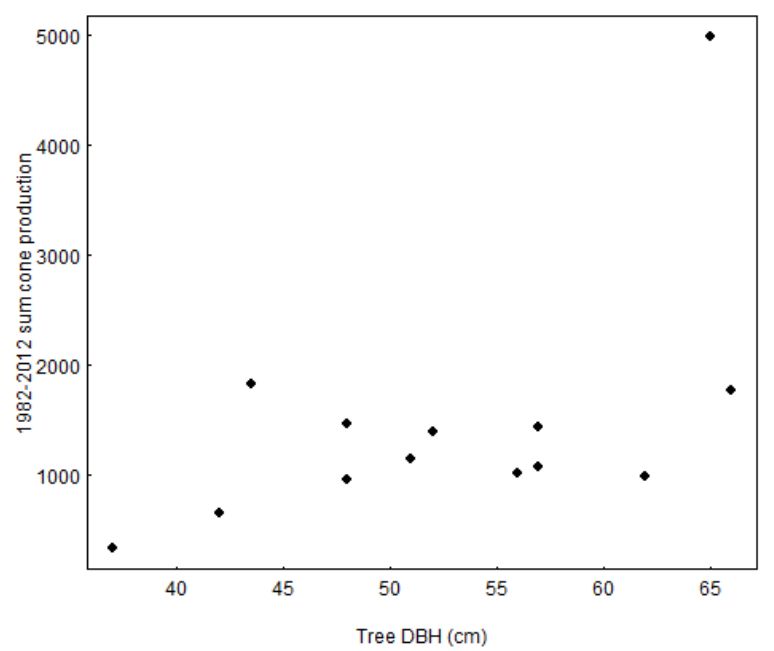

592 Supp. Figure 5. Relationship between tree diameter at breast height (DBH) and total cone production (1983593 2012)

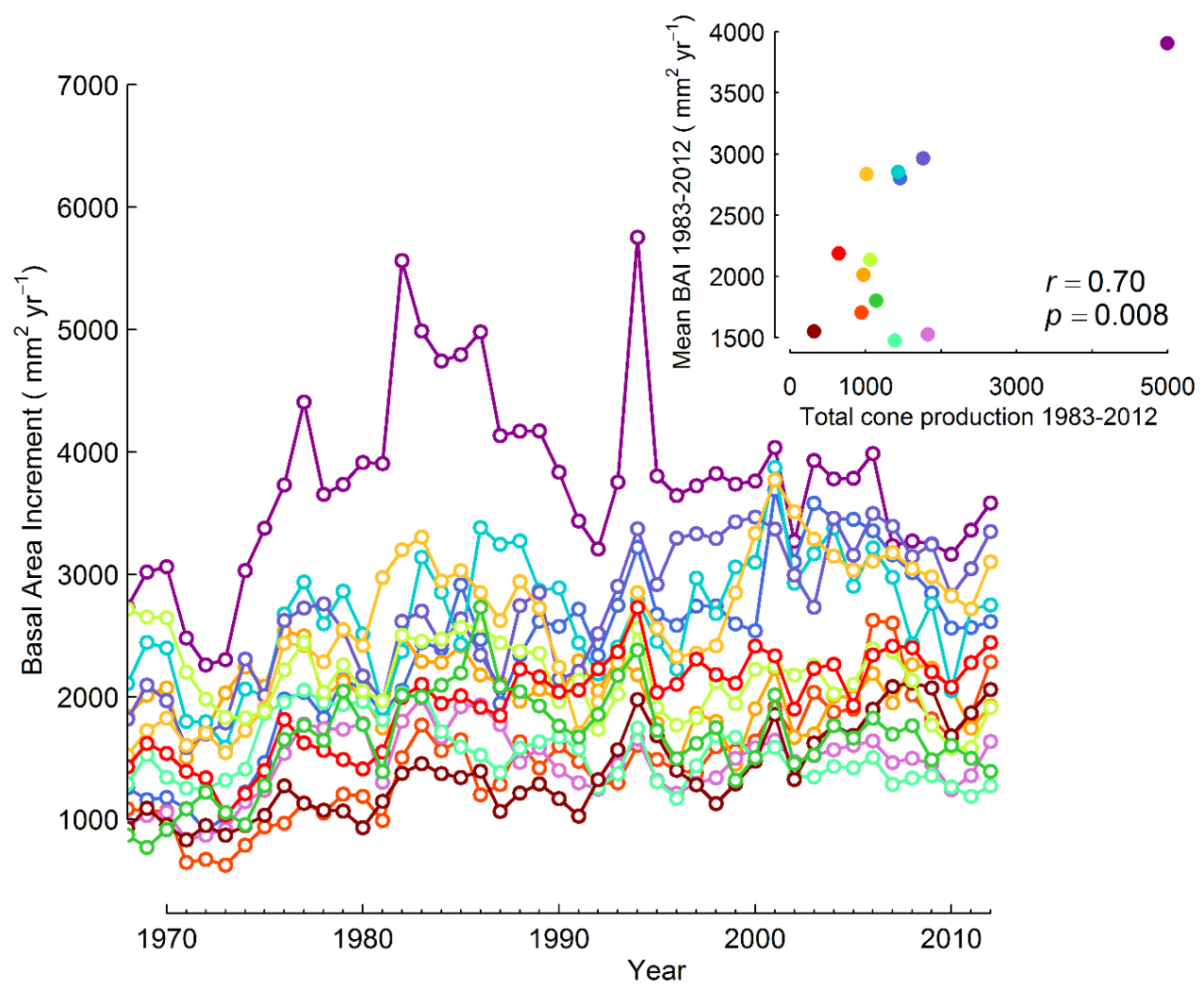

595

Supp. Figure 6. Basal Area Increment (BAI) chronologies for each individual. Line colour represents the individual tree ranking for total 1983-2012 cone count; heavy cone producers are purple/blue, and light producers are orange/red. Inset plot shows the relationship between total cone production (1983-2012) and individual tree BAI over the same time period. 

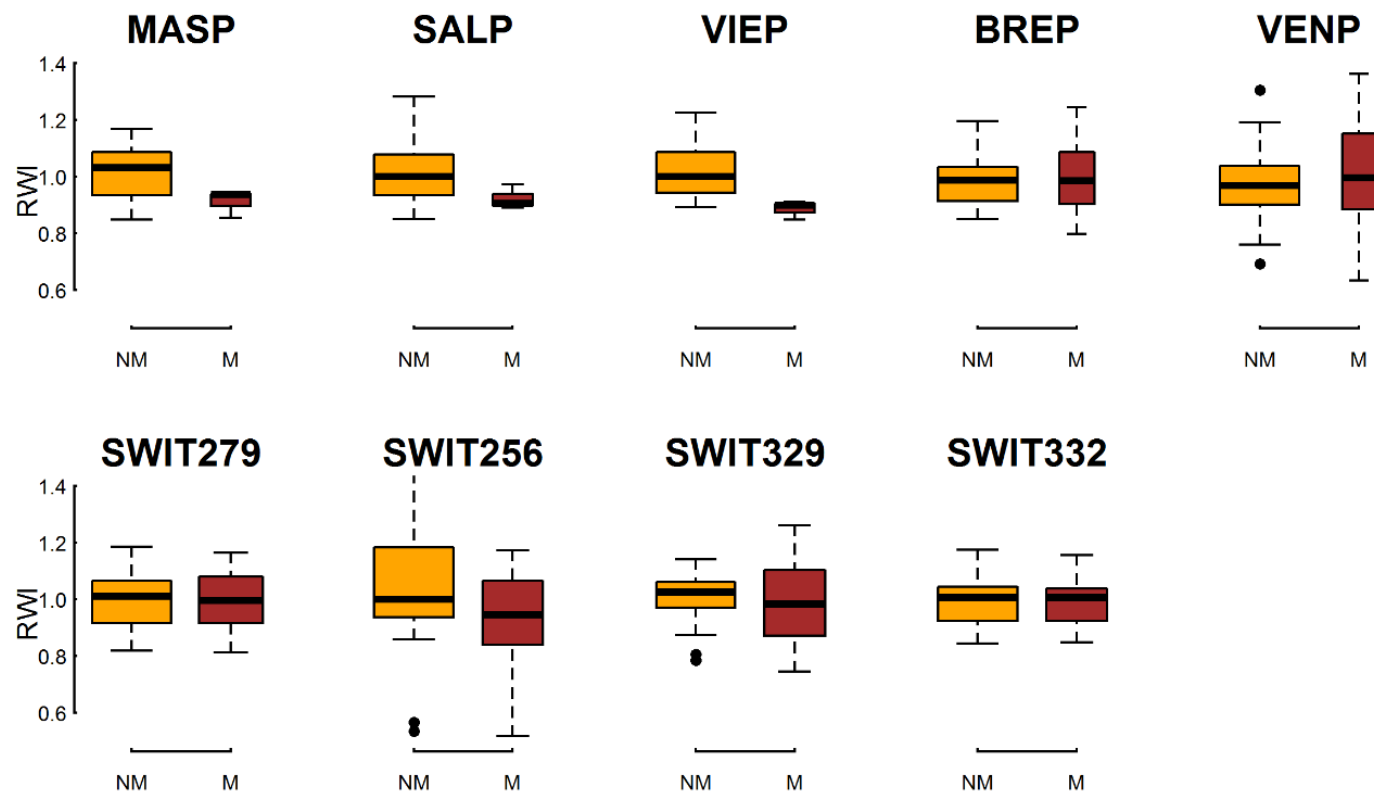

600

601

Supp. Figure 7. Boxplots of RWI according to regional masting category (mast years taken from the MASTREE database for ITC, ITH and $\mathrm{CHO}$ ). Orange = non-mast year, brown = mast year .
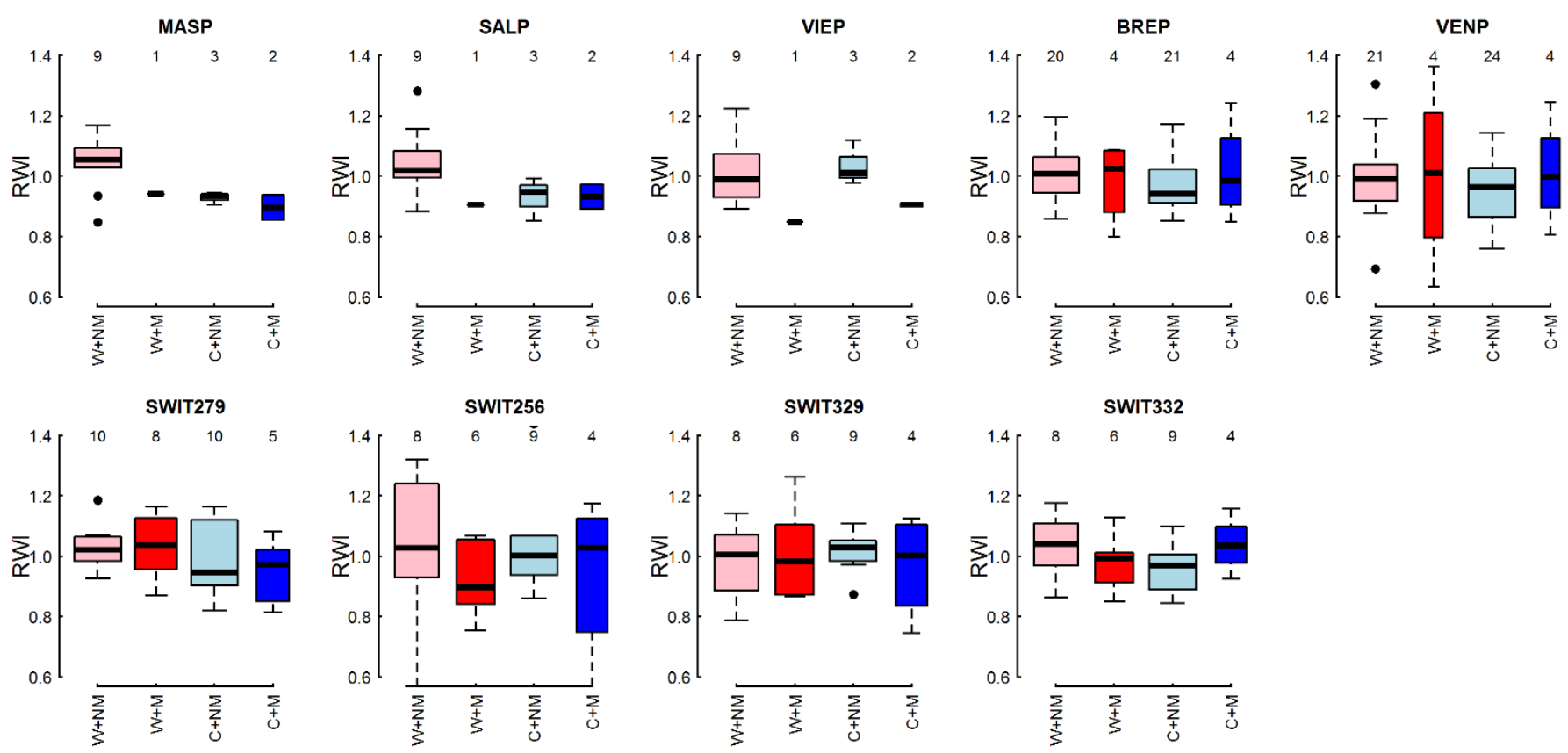

Sup. Figure 8. Boxplots of RWI according to summer temperature and masting. Red = warm summers (W), 

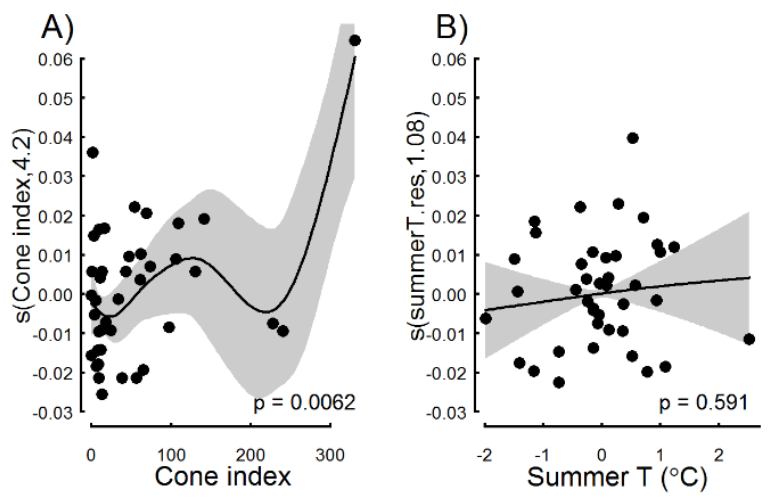

610 Supp. Figure 9. GAM models with 95\% confidence intervals for between-tree growth CV and A) cone index,

611 B) summer temperature. The smoother for Cone Index is significant, showing an increase in growth CV (a

612 decline in synchrony) in years of high seed production at the stand level, but not significant relationship with 613 summer temperature (May-July). 

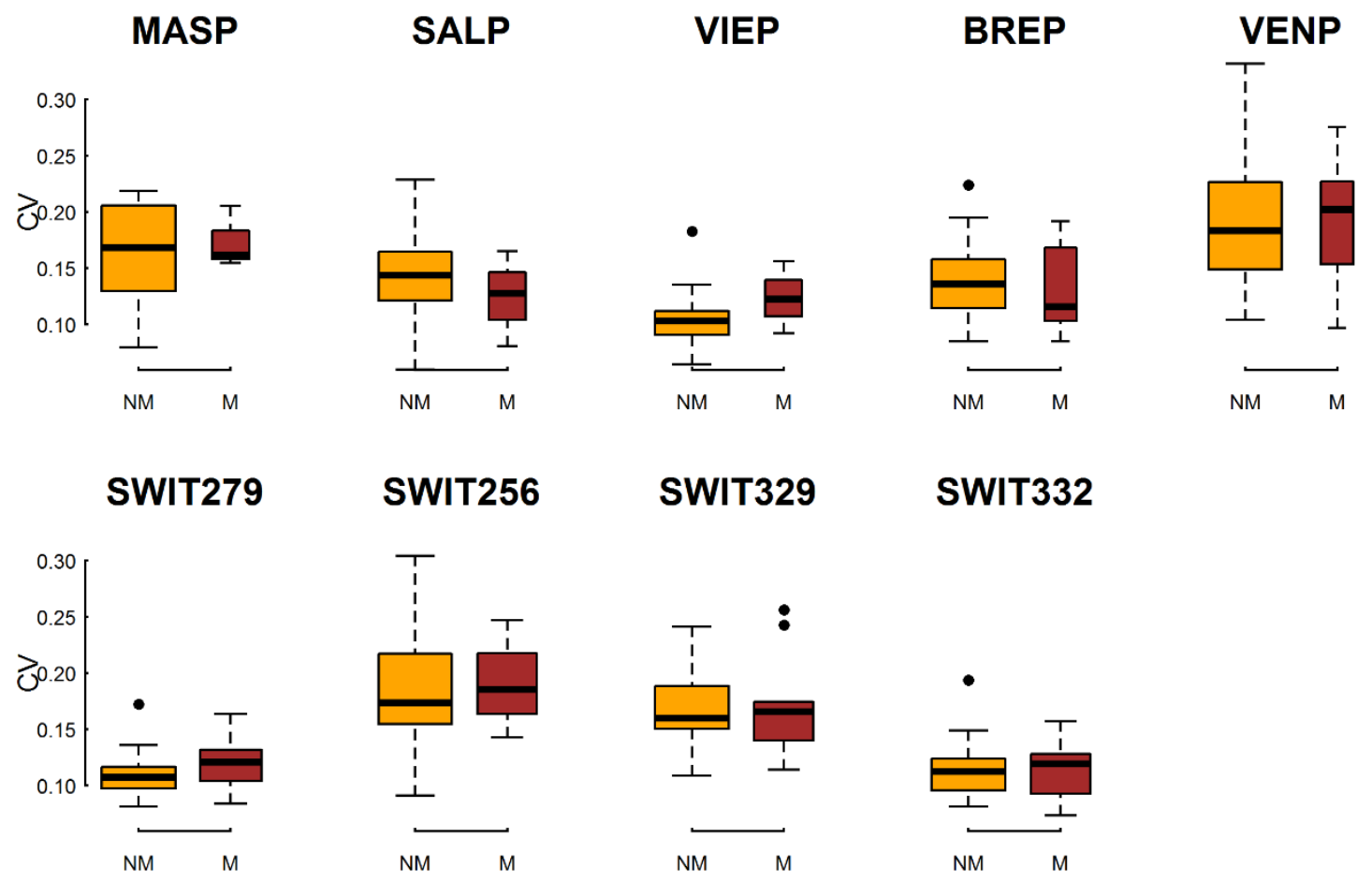

\section{SWIT329}

SWIT332

620

621 Supp. Figure 10. Boxplots of $\mathrm{CV}_{\mathrm{RWI}}$ according to masting status in Alpine spruce tree ring chronologies. No 622 differences were statistically significant (Wilcoxon tests). Orange = non-mast year, brown = mast year 623 624 
Allen, R. B., Hurst, J. M., Portier, J. and Richardson, S. J. (2014) 'Elevation-dependent responses of tree mast seeding to climate change over 45 years', Ecology and Evolution, 4(18), pp. 3525-3537.

Allen, R. B., Millard, P. and Richardson, S. J. (2017) 'A Resource Centric View of Climate and Mast Seeding in Trees', in Cánovas, F., Lüttge, U. and Matyssek, R. (eds.) Progress in Botany. Cham: Springer.

Ascoli, D., Maringer, J., Hacket-Pain, A., Conedera, M., Drobyshev, I., Motta, R., Cirolli, M., Kantorowicz, W., Zang, C., Schueler, S., Croisé, L., Piussi, P., Berretti, R., Palaghianu, C., Westergren, M., Lageard, G.A., J., Burkart, A., Bichsel, R. G., Thomas, P. A., Beudert, B., Övergaard, R. and Vacchiano, G. (2017a) 'Two centuries of masting data for European beech and Norway spruce across the European continent', Ecology, 98(5), pp. 1473.

Ascoli, D., Vacchiano, G., Turco, M., Conedera, M., Drobyshev, I., Maringer, J., Motta, R. and Hacket-Pain, A. (2017b) 'Inter-annual and decadal changes in teleconnections drive continental-scale synchronization of tree reproduction', Nature Communications, 8.

Auer, I., Bohm, R., Jurkovic, A., Lipa, W., Orlik, A., Potzmann, R., Schoner, W., Ungersbock, M., Matulla, C., Briffa, K., Jones, P., Efthymiadis, D., Brunetti, M., Nanni, T., Maugeri, M., Mercalli, L., Mestre, O., Moisselin, J. M., Begert, M., Muller-Westermeier, G., Kveton, V., Bochnicek, O., Stastny, P., Lapin, M., Szalai, S., Szentimrey, T., Cegnar, T., Dolinar, M., Gajic-Capka, M., Zaninovic, K., Majstorovic, Z. and Nieplova, E. (2007) 'HISTALP - historical instrumental climatological surface time series of the Greater Alpine Region', International Journal of Climatology, 27(1), pp. 17-46.

Barringer, B. C., Koenig, W. D. and Knops, J. M. H. (2013) 'Interrelationships among life-history traits in three California oaks', Oecologia, 171(1), pp. 129-139.

Berdanier, A. B. and Clark, J. S. (2016) 'Divergent reproductive allocation trade-offs with canopy exposure across tree species in temperate forests', Ecosphere, 7(6), pp. 10.

Bogdziewicz, M., Zwolak, R. and Crone, E. E. (2016) 'How do vertebrates respond to mast seeding?', Oikos, 125(3), pp. 300-307.

Brooke, J. M., Basinger, P. S., Birckhead, J. L., Laskley, M. A., McGord, J. M., Nanney, J. S. and Harper, G. A. (2019) 'Effects of fertilization and crown release on white oak (Quercus alba) masting and acorn quality', Forest Ecology and Management, 433, pp. 305-312.

Bunn, A. G. (2008) 'A dendrochronology program library in R (dplR)', Dendrochronologia, 26(2), pp. 115-124.

Buras, A., Schunk, C., Zeitrag, C., Herrmann, C., Kaiser, L., Lemme, H., Straub, C., Taeger, S., Gosswein, S., Klemmt, H. J. and Menzel, A. (2018) 'Are Scots pine forest edges particularly prone to drought-induced mortality?', Environmental Research Letters, 13(2).

Caignard, T., Kremer, A., Firmat, C., Nicolas, M., Venner, S. and Delzon, S. (2017) 'Increasing spring temperatures favor oak seed production in temperate areas', Scientific Reports, 7, pp. 8555.

Carrer, M. (2011) 'Individualistic and Time-Varying Tree-Ring Growth to Climate Sensitivity', Plos One, 6(7).

Carrer, M., Castagneri, D., Prendin, A. L., Petit, G. and von Arx, G. (2017) 'Retrospective Analysis of Wood Anatomical Traits Reveals a Recent Extension in Tree Cambial Activity in Two High-Elevation Conifers', Frontiers in Plant Science, 8. 
Castagneri, D., Nola, P., Motta, R. and Carrer, M. (2014) 'Summer climate variability over the last 250 years differently affected tree species radial growth in a mesic Fagus-Abies-Picea old-growth forest', Forest Ecology and Management, 320, pp. 21-29.

Cook, E. R. and Peters, K. (1981) 'The Smoothing Spline: A New Approach to Standardizing Forest Interior Tree-Ring Width Series for Dendroclimatic Studies', Tree-Ring Bulletin, 41, pp. 45-53.

Davi, H., Cailleret, M., Restoux, G., Amm, A., Pichot, C. and Fady, B. (2016) 'Disentangling the factors driving tree reproduction', Ecosphere, 7(9).

Deslauriers, A., Rossi, S., Anfodillo, T. and Saracino, A. (2008) 'Cambial phenology, wood formation and temperature thresholds in two contrasting years at high altitude in southern Italy', Tree Physiology, 28(6), pp. 863-871.

Despland, E. and Houle, G. (1997) 'Climate influences on growth and reproduction of Pinus banksiana (Pinaceae) at the limit of the species distribution in eastern North America', American Journal of Botany, 84(7), pp. 928-937.

Drobyshev, I., Niklasson, M., Mazerolle, M. J. and Bergeron, Y. (2014) 'Reconstruction of a 253-year long mast record of European beech reveals its association with large scale temperature variability and no longterm trend in mast frequencies', Agricultural and Forest Meteorology, 192, pp. 9-17.

Greene, D. F., Messier, C., Asselin, H. and Fortin, M. J. (2002) 'The effect of light availability and basal area on cone production in Abies balsamea and Picea glauca', Canadian Journal of Botany-Revue Canadienne De Botanique, 80(4), pp. 370-377.

Grissino-Mayer, H. D. (2001) 'Crossdating accuracy: A manual and tutorial for the computer program COFECHA', Tree-Ring Research, 57, pp. 205-221.

Hacket-Pain, A. J., Ascoli, D., Vacchiano, G., Biondi, F., Cavin, L., Conedera, M., Dro byshev, I., Dorado Liñán, I., Friend, A. D., Grabner, M., Hartl, I., Kreyling, J., Lebourgeois, F., Levanič, T., Menzel, A., van der Maaten, E., van, der Maaten-Theunissen, M., Muffler, L., Motta, R., Roibu, C., Popa, I., Scharnweber, T., Weigel, R., W' Wilmking, M. and $^{\mathrm{Z}} \mathrm{a}^{\mathrm{ng}}$, C. S. (2018) 'Climatically controlled reproduction drives interannual growth variability in a temperate tree species', Ecology Letters, 21, 1833-1844.

Hacket-Pain, A. J., Lageard, J. G. A. and Thomas, P. A. (2017) 'Drought and reproductive effort interact to control growth of a temperate broadleaved tree species (Fagus sylvatica)', Tree Physiology, 37(6), pp. 744754.

Han, Q., Kagawa, A., Kabeya, D. and Inagaki, Y. (2016) 'Reproduction-related varaition in carbon allocation to woody tissues in Fagus crenata using a natural ${ }^{13} \mathrm{C}$ approach', Tree Physiology, 36, pp. 1343-1352.

Harris, I., Jones, P. D., Osborn, T. J. and Lister, D. H. (2014) 'Updated high-resolution grids of monthly climatic observations - the CRU TS3.10 Dataset', International Journal of Climatology, 34(3), pp. 623-642.

Hayat, A., Hacket-Pain, A. J., Pretzsch, H., Rademacher, T. T. and Friend, A. D. (2017) 'Modeling Tree Growth Taking into Account Carbon Source and Sink Limitations', Frontiers in Plant Science, 8.

Healy, W. M., Lewis, A. M. and Boose, E. F. (1999) 'Variation of red oak acorn production', Forest Ecology and Management, 116(1-3), pp. 1-11. 
Herrera, C. M., Jordano, P., Guitian, J. and Traveset, A. (1998) 'Annual variability in seed production by woody plants and the masting concept: Reassessment of principles and relationship to pollination and seed dispersal', American Naturalist, 152(4), pp. 576-594.

Hoch, G. (2005) 'Fruit-bearing branchlets are carbon autonomous in mature broad-leaved temperate forest trees', Plant Cell and Environment, 28(5), pp. 651-659.

Kelly, D. and Sork, V. L. (2002) 'Mast seeding in perennial plants: Why, how, where?', Annual Review of Ecology and Systematics, 33, pp. 427-447.

Koenig, W. D. and Knops, J. M. H. (2000) 'Patterns of annual seed production by northern hemisphere trees: A global perspective', American Naturalist, 155(1), pp. 59-69.

Koenig, W. D., Knops, J. M. H., Carmen, W. J. and Pearse, I. S. (2015) 'What drives masting? The phenological synchrony hypothesis', Ecology, 96(1), pp. 184-192.

Krouchi, F., Derridj, A. and Lefevre, F. (2004) 'Year and tree effect on reproductive organisation of Cedrus atlantica in a natural forest', Forest Ecology and Management, 197(1-3), pp. 181-189.

LaMontagne, J. M. and Boutin, S. (2007) 'Local-scale synchrony and variability in mast seed production patterns of Picea glauca', Journal of Ecology, 95(5), pp. 991-1000.

LaMontagne, J. M. and Boutin, S. (2009) 'Quantitative methods for defining mast-seeding years across species and studies', Journal of Vegetation Science, 20(4), pp. 745-753.

Linhart, Y. B. and Mitton, J. B. (1985) 'RELATIONSHIPS AMONG REPRODUCTION, GROWTH-RATES, AND PROTEIN HETEROZYGOSITY IN PONDEROSA PINE', American Journal of Botany, 72(2), pp. 181-184.

Lucas-Borja, M. E. and Vacchiano, G. (2018) 'Interactions between climate, growth and seed production in Spanish black pine (Pinus nigra Arn. ssp salzmannii) forests in Cuenca Mountains (Spain)', New Forests, 49(3), pp. 399-414.

Medlyn, B. E., Dreyer, E., Ellsworth, D., Forstreuter, M., Harley, P. C., Kirschbaum, M. U. F., Le Roux, X., Montpied, P., Strassemeyer, J., Walcroft, A., Wang, K. and Loustau, D. (2002) 'Temperature response of parameters of a biochemically based model of photosynthesis. II. A review of experimental data', Plant Cell and Environment, 25(9), pp. 1167-1179.

Mencuccini, M. and Piussi, P. (1995) 'Production of Seeds and Cones and Consequences for Wood Radial Increment in Norway Spruce (Picea Abies (L.) Karst.)', Giornale Botanico Italiano, 129(3), pp. 797-812.

Mencuccini, M., Piussi, P. and Sulli, A. Z. (1995) '30 YEARS OF SEED PRODUCTION IN A SUB-ALPINE NORWAY SPRUCE FOREST - PATTERNS OF TEMPORAL AND SPATIAL VARIATION', Forest Ecology and Management, 76(1-3), pp. 109-125.

Minor, D. M. and Kobe, R. K. (2017) 'Masting synchrony in northern hardwood forests: super-producers govern population fruit production', Journal of Ecology, 105(4), pp. 987-998.

Monks, A. and Kelly, D. (2006) 'Testing the resource-matching hypothesis in the mast seeding tree Nothofagus truncata (Fagaceae)', Austral Ecology, 31(3), pp. 366-375. 
Mund, M., Kutsch, W. L., Wirth, C., Kahl, T., Knohl, A., Skomarkova, M. V. and Schulze, E. D. (2010) 'The influence of climate and fructification on the inter-annual variability of stem growth and net primary productivity in an old-growth, mixed beech forest', Tree Physiology, 30(6), pp. 689-704.

Obeso, J. R. (2002) 'The costs of reproduction in plants', New Phytologist, 155(3), pp. 321-348.

Ostfeld, R. S. and Keesing, F. (2000) 'Pulsed resources and community dynamics of consumers in terrestrial ecosystems', Trends in Ecology \& Evolution, 15(6), pp. 232-237.

Overgaard, R., Gemmel, P. and Karlsson, M. (2007) 'Effects of weather conditions on mast year frequency in beech (Fagus sylvatica L.) in Sweden', Forestry, 80(5), pp. 553-563.

Patterson, T. and Knapp, P. (2018) 'Long-leaf pine cone-radial growth relationships in the southeastern USA', Dendrochronologia, 50, pp. 134-141.

Pearse, I. S., Koenig, W. D. and Kelly, D. (2016) 'Mechanisms of mast seeding: resources, weather, cues, and selection', New Phytologist, 212(3), pp. 546-562.

Pearse, I. S., LaMontagne, J. M. and Koenig, W. D. (2017) 'Inter-annual variation in seed production has increased over time (1900-2014)', Proceedings of the Royal Society B-Biological Sciences, 284(1868).

Piussi, P. (1988) Accrescimento e sopravvivenza del novellame di Picea in tagliate a raso a buca.

R Development Core Team (2016) R: A language and environment for statistical computing. 3.3.1 edn. Vienna, Austria: R Foundation for Statistical Computing.

Rodríguez-Ramírez, E. C., Terrazas, T. and Luna-Vega, I. (2018) 'The influence of climate on the masting behavior of Mexican beech: growth rings and xylem anatomy', Trees, Early View.

Seifert, T. and Mueller-Starck, G. (2009) 'Impacts of fructification on biomass production and correlated genetic effects in Norway spruce (Picea abies L. Karst.)', European Journal of Forest Research, 128(2), pp. 155-169.

Selas, V., Piovesan, G., Adams, J. M. and Bernabei, M. (2002) 'Climatic factors controlling reproduction and growth of Norway spruce in southern Norway', Canadian Journal of Forest Research-Revue Canadienne De Recherche Forestiere, 32(2), pp. 217-225.

Sletvold, N. and Agren, J. (2015) 'Climate-dependent costs of reproduction: Survival and fecundity costs decline with length of the growing season and summer temperature', Ecology Letters, 18(4), pp. 357-364.

Taylor, B. (2016) cruts: Interface to climatic research unit time-series version 3.21 data (Version R package version 0.3.). Available at: https://CRAN.R-project.org/package=cruts (Accessed: 1 September 2016).

Thomas, S. C. (2011) 'Age-Related Changes in Tree Growth and Functional Biology: The Role of Reproduction', in Meinzer, F., Lachenbruch, B. and Dawson, T. (eds.) Size- and Age-Related Changes in Tree Structure and Function: Dordrecht, pp. 33-64.

Vacchiano, G., Ascoli, D., Berzaghi, F., Lucas-Borja, M. E., Caignard, T., Collalti, A., Mairota, P., Palaghianu, C., Reyer, C. P. O., Sanders, T. G. M., Schermer, E., Wohlgemuth, T. and Hacket-Pain, A. (2018) 'Reproducing reproduction: How to simulate mast seeding in forest models', Ecological Modelling, 376, pp. 40-53. 
827 Vacchiano, G., Hacket-Pain, A., Turco, M., Motta, R., Maringer, J., Conedera, M., Drobyshev, I. and Ascoli, D. 828 (2017) 'Spatial patterns and broad-scale weather cues of beech mast seeding in Europe', New Phytologist, 829 215(2), pp. 595-608.

831 Villellas, J. and Garcia, M. B. (2018) 'Life-history trade-offs vary with resource availability across the 832 geographic range of a widespread plant', Plant Biology, 20(3), pp. 483-489.

834 Zang, C. (2018) histalp - Extract HISTALP grid data for coordinate pairs. R package version 1.0.0, URL 835 http://github.com/cszang/histalp,DOI: 10.5281/zenodo.1313450.

Zywiec, M. and Zielonka, T. (2013) 'Does a heavy fruit crop reduce the tree ring increment? Results from a 838 12-year study in a subalpine zone', Trees-Structure and Function, 27(5), pp. 1365-1373. 